\title{
EFFECT OF ACID BUFFERING CAPACITY ON THE LONG-TERM MOBILITY OF HEAVY METALS IN CLAY LINER
}

\author{
Huyuan Zhangi), Masashi Kamon ${ }^{\text {ii) }}$ and TAKeshi Katsumi ${ }^{\text {iii) }}$
}

\begin{abstract}
The $\mathrm{pH}$ and Eh effects on the mobility of zinc within landfill clay liner are investigated by modified batch tests on Osaka marine clay with cultivation of native microorganisms in the soil. The long-term mobility of zinc in landfill clay liner is discussed based on the $\mathrm{pH}$ buffering capacity of liner soil-leachate system. Tests results show that both $\mathrm{pH}$ and Eh conditions control the mobility of zinc in Osaka marine clay. Low redox potentials and neutral to basic $\mathrm{pH}$ conditions in landfill sites tend to prompt the insolubilization of zinc in landfill liner, in particular in the case where marine clay is used to serve as a natural liner material at offshore landfill sites. In the long-term perspective, oxygen will intrude finally into the landfill, which switches the anaerobic decomposition into an aerobic one and results a decrease in $\mathrm{pH}$. Titration test results indicate that the newly generated leachate has a higher acid buffering capacity than the aged leachate, while leachates from MSW incineration ash have high hydroxides alkalinity at $\mathrm{pH}>8$. Test results reveal that both of the wastes and clay liner possess enough acid buffering capacity to consume the protons produced in organic oxidation reactions. Therefore, high levels of remobilization of heavy metals are not expected in the long-term perspective.
\end{abstract}

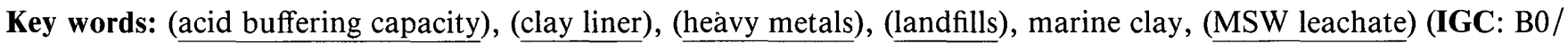
B12)

\section{INTRODUCTION}

Heavy metals in landfill leachate possess a potential threat to the nearby environment around landfill sites. A lot of monitoring data available show that most heavy metals concentration in landfill leachate are very low, that is, heavy metals are not of a major concern from environmental impact viewpoint (Kjeldsen et al., 2002). This is because, low redox potentials and neutral to basic $\mathrm{pH}$ conditions in landfill sites tend to prompt the effective immobilization of heavy metals and also potentially decrease the hydraulic conductivity of bottom clay barrier layer (Kamon et al., 2002a, 2002b). In the longterm perspective, for example 30-50 years which are the typical durations for landfill management, oxygen will intrude finally into landfills, switching the anaerobic decomposition into the aerobic one. Most oxidation of organic carbon results in a net release of $\mathrm{CO}_{2}$, which will force the $\mathrm{pH}$ to decrease in a system that is not in equilibrium with the atmosphere. This means that the long-term stabilization process in landfills is an acidification process from chemical viewpoint. During this process the metals immobilized previously tend to have remobilized and leached out in response to the alterations to the environment, a phenomenon referred to as "chemical time bomb" (Stigliani et al., 1991). Clearly, the acid buffering capacity $(\mathrm{ABC})$ of landfilled wastes, to a great extent, controls the $\mathrm{pH}$ decrease, and therefore plays an important role in preventing the remobilization of heavy metals from occurring.

Besides the waste body itself, bottom clay liners underlying the waste layers play an important role in leachate attenuation. Clay liner contains high content of clay fraction, which can effectively retard the pollutants in leachate by various physical and chemical processes. Also, landfill clay liner provides a perfect environment where biochemical reactions occur intensively because of the plenteous carbon sources for microbial growth and the long contact time between microbes and slow penetrating leachate. Any comprehensive evaluations about the environmental impact of heavy metal from landfill sites require a profound understanding of the attenuation mechanisms of heavy metal within clay liner, especially in the case that the attenuation functions of the waste layers are depleted. The objectives of this research are to discuss the effect of acid buffering capacity $(\mathrm{ABC})$

i) Professor, College of Environmental Science and Engineering, Hohai University, Nanjing 210098, China (formerly JSPS Research Fellow, Graduate School of Global Environmental Studies, Kyoto University, Sakyo-ku, Kyoto 606-8501, Japan).

ii) Professor, Graduate School of Global Environmental Studies, Kyoto University, Sakyo-ku, Kyoto 606-8501, Japan (kamon@ geotech.gee.kyoto-u.ac.jp).

iii) Associate Professor, ditto (tkatsumi@mbox.kudpc.kyoto-u.ac.jp).

Manuscript was received for review on April 5, 2004.

Written discussions on this paper should be submitted before July 1, 2005 to the Japanese Geotechnical Society, 4-38-2, Sengoku, Bunkyo-ku, Tokyo 112-0011, Japan. Upon request the closing date may be extended one month. 


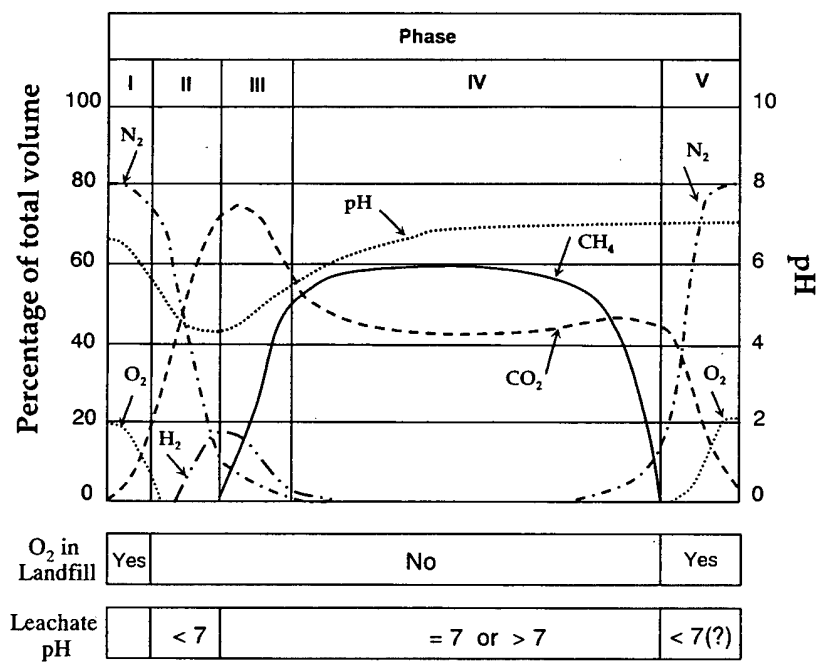

Fig. 1. Solid waste decomposition stages in landfills (After Farquhar and Rovers, 1973; Sarsby, 2000)

of liner-leachate system on the heavy metal mobility in clay liner in a long term perspective. In this study, $\mathrm{ABC}$ has been defined as acid titration to $\mathrm{pH}=3.0$.

\section{LANDFILL STABILIZATION}

The organic materials contained in municipal solid waste (MSW) are biodegradable and can be broken down into simpler compounds through chemical and microbiological actions. This stabilization process is well established based on both field and laboratory-scale data, and described as four phases (see Fig. 1).

During the first phase, which is relatively short, biodegradable organic materials react quickly with oxygen to form carbon dioxide, water, and other byproducts. Oxygen depletion marks the onset of anaerobic microbial processes, which persist much longer. The anaerobic phase, which is generally associated with methane gas production, is the dominant phase over the greater part of the landfill life and is more significant in terms of landfill stabilization. With respect to the landfill compositions and $\mathrm{pH}$ values of leachate produced during waste decomposition, the anaerobic phase of landfill life in turn can be divided into three sub-phases: the anaerobic acid phase (phase II), the initial methane production phase (phase III) and the stable methane production phase (phases IV). Phase II is usually characterized by a lower $\mathrm{pH}$ values of $4.5 \sim 7.5$, while the phases III and IV are characterized by a higher $\mathrm{pH}$ values of $7.5 \sim 9.0$ (Christensen et al., 2000).

The four phases of refuse decomposition described above have been defined on the basis of both field and laboratory-scale data. Recently, a subsequent phase of decomposition, the phase $\mathrm{V}$, is proposed based on theory or somewhat on speculation because no filed data are available to document it. During phase $\mathrm{V}$ it is believed that the air will begin to penetrate into the waste cell, turning the original anaerobic condition into an aerobic

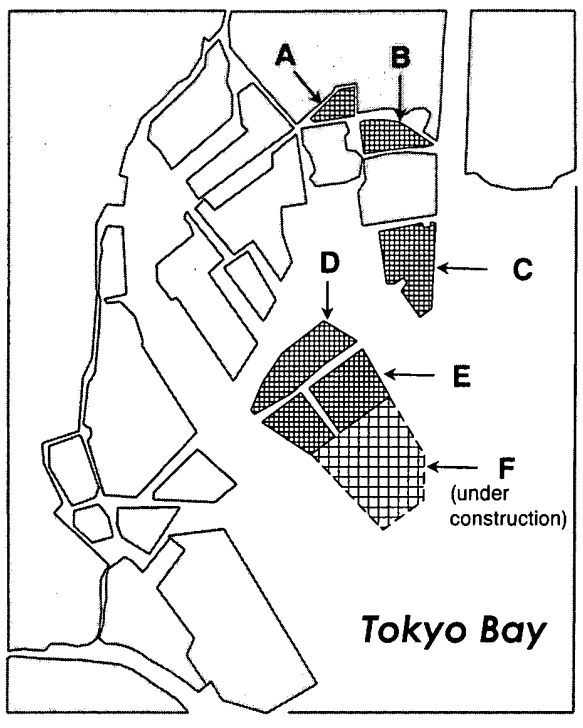

Fig. 2. Solid waste landfill sites in Tokyo Bay

one (referred to as mature aerobic phase). Since the remaining substrate in this phase becomes more and more resistant to degradation, mainly humic substances, phase $\mathrm{V}$ is also called the humic phase (Bozkurt et al., 2000).

Japan has practiced landfilling technology for several decades, and attributes a great deal to its development. The creative innovations, for example, include coastal landfill facilities constructed to contain municipal and industrial wastes, particularly in the Tokyo and Osaka Bay. Landfilling of solid wastes in sea area in Japan is not only a means for final disposal of solid wastes, but also a stratagem for creating new land by site reclamation (Aburatani et al., 1996). Field investigation of the landfilled municipal solid waste sites in Tokyo Bay, Japan provides valuable documents for understanding the stabilization process in landfills. Figure 2 shows the location of the landfill sites investigated, namely, Landfill Sites A, B, C, and D. Figure 3 shows the waste settlement observed (Data from BPH, Tokyo M.G., 2001) at these 4 MSW landfill sites as indicated in Fig. 2. In order to compare the settlements of various landfills with different ages, the settlements observed are normalized to their thicknesses of the waste layer and shown in a unit of $\mathrm{mm}$ per 10 meters of solid waste thickness in one year (see Fig. 3). It can be found that after 20 years from the closure of the landfill sites the settlement of the landfilled wastes is less than $10 \mathrm{~mm} / 10 \mathrm{~m}$-waste/year; that is, the annual settlement of the waste is less than $0.1 \%$, which may be considered as stable from a geotechnical engineering viewpoint.

The temperature observed in the corresponding landfills at $20 \mathrm{~m}$ depth is shown in Fig. 4. Compared with the background geothermic temperature at the same depth in Tokyo Bay, it seems that the stabilization process within Landfill Site A has only completed after 20 years. In contrast, the other landfills are on their way that chemical or biochemical reactions are still occurring because net heat is transported to the nearby environment even after 


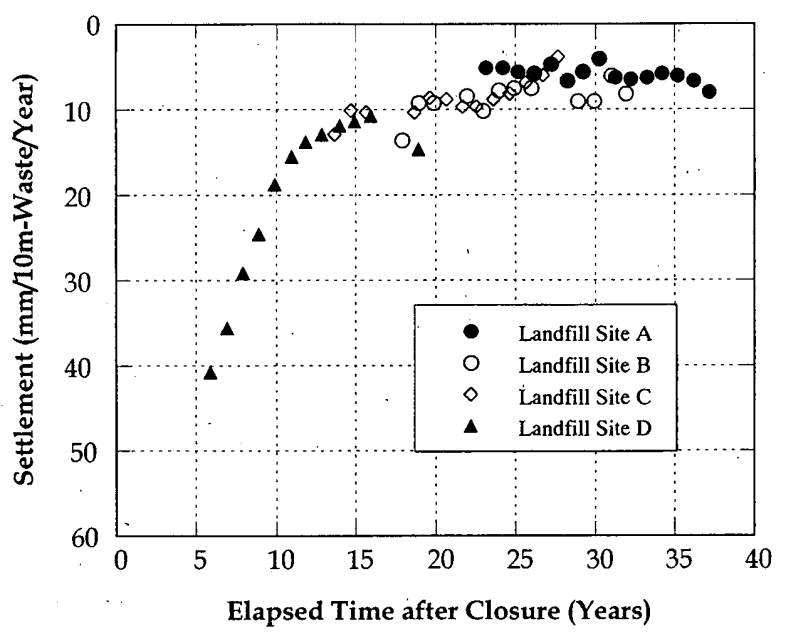

Fig. 3. Settlement vs landfill age for offshore MSW landfills in Tokyo Bay (Data from Bureau of Port and Harbor, Tokyo Metropolitan Government of Japan, 2001)

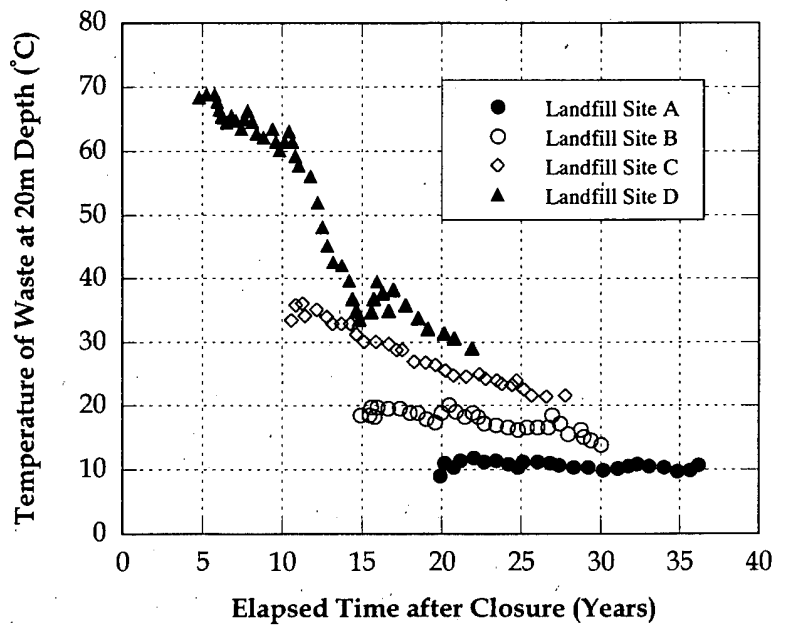

Fig. 4. Temperature vs landfill age for offshore MSW landfills in Tokyo Bay (Data from Bureau of Port and Harbor, Tokyo Metropolitan Government of Japan, 2001)

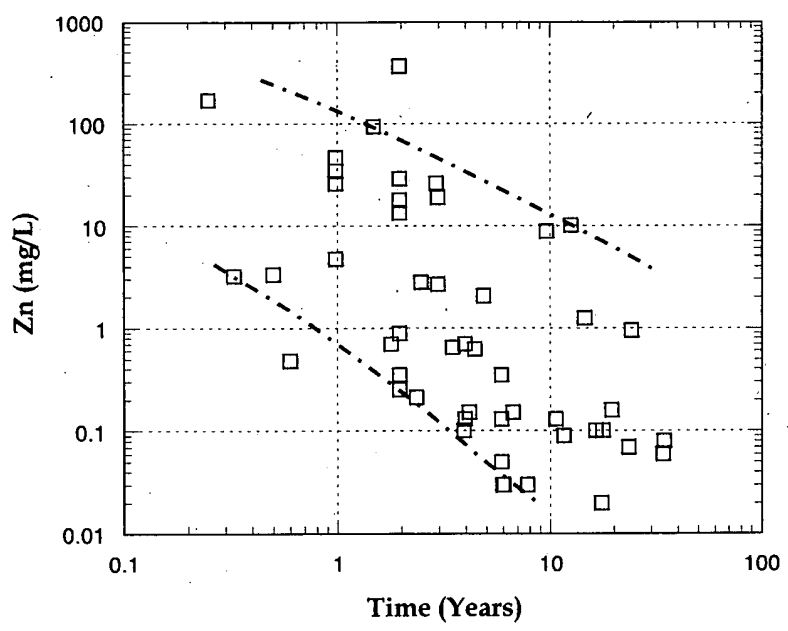

Fig. 5. Zinc concentration vs landfill age for several MSW landfill leachates (Data from Anderottola and Cannas, 1992)
Table 1. Acid producing and acid buffering reactions in wastes (Bozkurt et al., 2000)

\begin{tabular}{|c|c|}
\hline Type & Reactions \\
\hline \multicolumn{2}{|l|}{ Acid Producing: } \\
\hline Sulfides & $\begin{array}{l}\mathrm{FeS}+9 / 4 \mathrm{O}_{2}+3 / 2 \mathrm{H}_{2} \mathrm{O} \rightarrow \mathrm{FeOOH}+\mathrm{SO}_{4}^{2-}+2 \mathrm{H}^{+} \\
\mathrm{FeS}_{2}+15 / 4 \mathrm{O}_{2}+5 / 2 \mathrm{H}_{2} \mathrm{O} \\
\quad \rightarrow \mathrm{Fe}(\mathrm{OH})_{3(\mathrm{~s})}+2 \mathrm{SO}_{4}^{2-}+4 \mathrm{H}^{+}\end{array}$ \\
\hline Organic & $\mathrm{CH}_{2} \mathrm{O}+\mathrm{O}_{2} \rightarrow \mathrm{CO}_{2}+\mathrm{H}_{2} \mathrm{O} \rightarrow \mathrm{CO}_{3}^{2-}+2 \mathrm{H}^{+}$ \\
\hline \multicolumn{2}{|c|}{ Acid Consuming: } \\
\hline Carbonate minerals & $\mathrm{CaCO}_{3}+2 \mathrm{H}^{+} \rightarrow \mathrm{Ca}^{2+}+\mathrm{H}_{2} \mathrm{O}+\mathrm{CO}_{2}(\mathrm{pH}=6.2)$ \\
\hline Silicate minerals & $\begin{array}{l}\text { Primary rock minerals }+2 \mathrm{H}^{+}+\mathrm{H}_{2} \mathrm{O} \\
\quad \rightarrow \text { cations }+\mathrm{H}_{4} \mathrm{SiO}_{4}+\text { secondary minerals }\end{array}$ \\
\hline Cation exchange & $\mathrm{SO}: \mathrm{Me}+2 \mathrm{H}^{+} \rightarrow \mathrm{SO}: \mathrm{H}_{2}+\mathrm{Me}^{2+}(4.2=\mathrm{pH}<6.2)$ \\
\hline Aluminum & $\begin{array}{l}\mathrm{Al}_{2} \mathrm{O}_{3}+6 \mathrm{H}^{+} \rightarrow 2 \mathrm{Al}^{3+}+3 \mathrm{H}_{2} \mathrm{O}(3.8=\mathrm{pH}<4.2) \\
\mathrm{Al}(\mathrm{OH})_{3}+3 \mathrm{H}^{+} \rightarrow \mathrm{Al}^{3+}+3 \mathrm{H}_{2} \mathrm{O}\end{array}$ \\
\hline Iron & $\mathrm{Fe}_{2} \mathrm{O}_{3}+6 \mathrm{H}^{+} \rightarrow 2 \mathrm{Fe}^{3+}+3 \mathrm{H}_{2} \mathrm{O}(\mathrm{pH}<3.8)$ \\
\hline
\end{tabular}

$\mathrm{SO}=$ solid $; \mathrm{Me}=$ metal

Table 2. Estimated time to deplete all organic matter in a landfill in 10-m thick (Bozkurt et al., 2000)

\begin{tabular}{lc} 
Characteristics of the assumed landfill & $\begin{array}{c}\text { Time to deplete organic } \\
\text { (years) }\end{array}$ \\
\hline Waste partially saturated without a cover & 600 \\
Waste partially saturated with a cover & 30,000 \\
Waste fully saturated & $>500,000$ \\
\hline
\end{tabular}

20 years from the closure.

A similar time scale, around $20 \sim 30$ years, was observed by Anderottola and Cannas (1992) for the heavy metals in MSW landfill leachates to be attenuated to reach the environmental permitting limits (see Fig. 5 for the element zinc). Kjeldsen et al. (2002) reviewed the published data of MSW landfill leachate from some European countries, and concluded that most heavy metal concentrations in landfill leachate are at or below the US drinking water standards, such as $5 \mathrm{ppm}$ for $\mathrm{Zn}$.

Although disposal of solid waste by landfilling has been practiced for up to 60 years in the world, no engineered landfill cells available are reported to have changed to an aerobic condition by far. In consideration of the acid producing and acid buffering reactions in waste as listed in Table 1, Bozkurt et al. (2000) established a mathematic model to estimate the time scale that the wastes in a $10 \mathrm{~m}$ thick landfill deplete all organic matter due to oxygen penetration (see Table 2). As can be seen from Table 2 it takes centuries to many thousands of years that the organic matter in landfilled wastes will be depleted.

\section{MATERIALS AND METHODS}

Marine clay sampled from Osaka Bay was used for the experiment as a clay liner material because the marine clay is practically employed as a bottom barrier at the coastal landfill sites in Osaka Bay, Japan. The basic properties of the Osaka marine clay have been reported previously (Kamon et al., 2002). Zinc was selected as a 
Table 3. Basic properties of landfill leachates used

\begin{tabular}{crccc}
\hline Leachate & $\mathrm{pH}$ & Eh $(\mathrm{mV})$ & Wastes & Site \\
\hline L1 & 8.01 & -67 & MSW & Inland \\
L2 & 8.03 & -32 & MSW & Inland \\
L3 & 11.23 & -237 & MSWIA & Offshore \\
L4 & 11.32 & -281 & MSWIA & Offshore
\end{tabular}

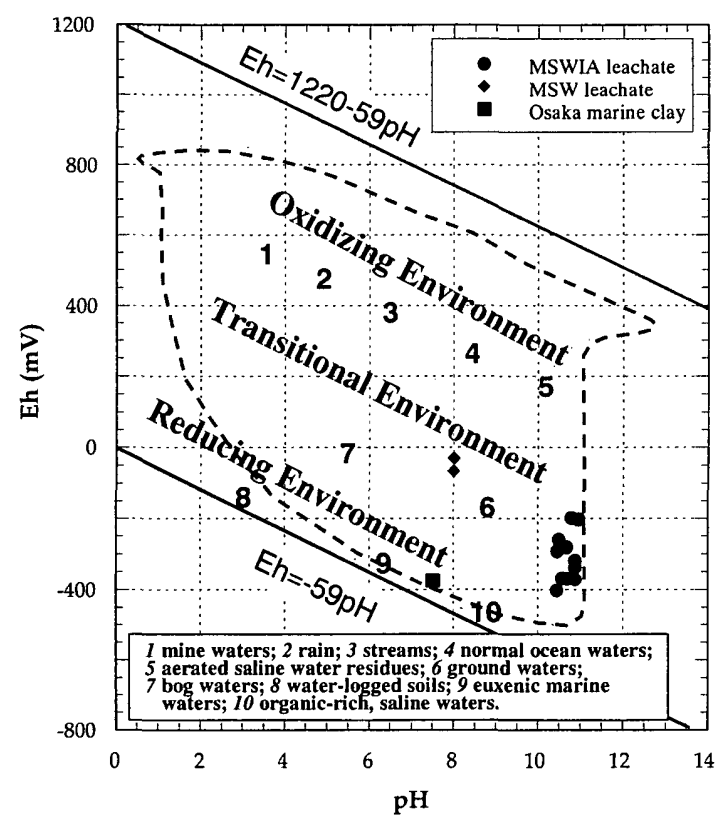

Fig. 6. pH and Eh conditions of the Osaka marine clay and landfill leachates used (Eh-pH diagram after Brookins, 1988)

target pollutant because it is a heavy. metal, which possesses biological toxicity and is mostly encountered in the leachate from both hazardous and municipal solid waste landfill sites.

Table 3 lists the basic properties of the four landfill leachates used in this study. Redox potential was measured by using the ORP meter (Horiba 6860-10C), having a Pt electrode with a standard electrode of $3.33 \mathrm{M}$ $\mathrm{KCl}-\mathrm{Ag} / \mathrm{AgCl}$. Leachates L1 and L2 were collected from two actual MSW landfills with different ages located in mountain area. Landfill for $\mathrm{L}_{1}$ is in operation while Landfill for L2 has been closed for $3 \sim 5$ years. Leachates L3 and L4 were collected from two different boreholes bored in the same landfill located in Osaka Bay, receiving mainly MSW incineration ash (MSWIA). The pH and Eh conditions of the Osaka marine clay and the landfill leachates used in this research are indicated in Fig. 6 in comparison with other natural soils and waters. Modified batch tests were conducted to evaluate the effects of both redox potential and $\mathrm{pH}$ on the solubility of metals. Acidimetric titration tests performed on the soil suspensions without microbe incubation were used to estimate the acid buffering capacity (ABC) of soil-leachate systems. Acidimetric titration tests performed on the soil suspensions with microbe incubation were used to understand the effect of organic carbon consumption by mi- crobes on $\mathrm{Zn}$ release.

\section{Modified Batch Tests}

Modified batch test, described in detail by Zhang (2001) and Kamon et al. (2002), allows cultivation of the native microorganisms in the soil used, and allows multiple sub-sampling of soil suspension after certain time intervals of incubation. To the soil suspensions used in batch tests, sodium acetate $\left(\mathrm{CH}_{3} \mathrm{COONa}\right)$ and ammonium dihydrogenphosphate $\left(\mathrm{NH}_{4} \mathrm{H}_{2} \mathrm{PO}_{3}\right)$ were added as nutrients to enhance the native bacteria life in soil sample; and ferric iron, nitrate and sulfate were added as alternative electron acceptors. Soil suspensions were bubbled continuously by nitrogen gas or by oxygen gas to induce a reducing or an oxidizing respiration, respectively. After certain incubation duration, around 10-15 $\mathrm{mL}$ of soil suspension was sub-sampled, centrifuged, filtered through a $0.45 \mu \mathrm{m}$ pore size. Filtered solution was analyzed for $\mathrm{Zn}$ by inductively coupled plasma spectrometry (ICPS-8000, Shimadzu).

\section{Acid Titration Tests on Soil Suspensions without Incuba- tion}

Osaka marine clay was dispersed in different solutions, including MSW leachates L1 and L2 and distilled water, with different solid/liquid ratio, such as $0,1: 50$, and 1:10. As soon as the soil suspensions were prepared, they were titrated with $0.1 \mathrm{M} \mathrm{HNO}_{3}$ immediately by an automatic titrating device (Auto Titrator COM-1500, Hiranuma) to evaluate their acid buffering capacity $(A B C)$, which is defined as acid titration to $\mathrm{pH}=3.0$ in this study. The reason to use acid titration to $\mathrm{pH}=3.0$ will be discussed in the chapter "Results and Discussions."

Acid Titration Tests on Soil Suspensions with Incubation

Osaka marine clay was dispersed in MSWIA leachates L3 and L4 with a solid/liquid ratio of 1:10 to prepare soil suspensions, namely, Q1, Q2, Q3, and Q4 for acid titration tests. To investigate the organic load effect on $\mathrm{ABC}$, suspensions Q2 and Q4 were enhanced with nutrients in comparison with suspensions Q1 and Q3, respectively (see Table 4). Zinc was added to all suspensions as one of the representative heavy metals founded in landfill leachate. Soluble $\mathrm{Zn}$ concentrations were analyzed during titration tests to establish the relationship between $\mathrm{Zn}$ release and $\mathrm{ABC}$. Soil suspensions were incubated as the same as that described previously in the modified batch test but nitrogen gas bubbling was used firstly and followed by opening the reactor to the air after 35 days. After certain incubation duration time, soil suspension was sub-sampled and titrated with $0.1 \mathrm{M}$ $\mathrm{HNO}_{3}$ by an automatic titrating device (Auto Titrator COM-1500, Hiranuma). As soon as the pH decreased to a specific value, such as $7.0,6.0,5.0,4.0$ or 3.0 , during the titration test, around $2 \mathrm{~mL}$ of suspension was withdrawn out with a syringe, centrifuged, and filtered through a $0.45 \mu \mathrm{m}$ pore size. Filtered solution was analyzed for total organic carbon (TOC) by Total Organic Carbon Analyzer (TOC-5050A, Shimadzu), and 
Table 4. Conditions used in titration test on soil suspensions with incubation

\begin{tabular}{lrrrr}
\hline Sample Number & Q1 & Q2 & \multicolumn{1}{c}{ Q3 } & \multicolumn{1}{c}{ Q4 } \\
\hline Solid: Liquid Ratio & $1: 10$ & $1: 10$ & $1: 10$ & $1: 10$ \\
Natural Wet Clay (g) & 200 & 200 & 200 & 200 \\
Equivalent Dry Clay (g) & 100 & 100 & 100 & 100 \\
Natural Water (mL) & 100 & 100 & 100 & 100 \\
$\mathrm{CH}_{3} \mathrm{COONa}_{(\mathrm{ppm})}$ & - & 3000 & - & 3000 \\
$\mathrm{NH}_{4} \mathrm{H}_{2} \mathrm{PO}_{3}(\mathrm{ppm})$ & - & 300 & - & 300 \\
$\mathrm{Na}_{2} \mathrm{SO}_{4}(\mathrm{ppm})$ & - & 1000 & - & 1000 \\
$\mathrm{ZnCl}_{2}(\mathrm{ppm})$ & 1000 & 1000 & 1000 & 1000 \\
Leachate $\mathrm{L3}(\mathrm{mL})$ & 900 & 900 & - & - \\
Leachate L4 (mL) & - & - & 900 & 900 \\
Total Suspension (mL) & 1000 & 1000 & 1000 & 1000 \\
Bubbling Gas Shift & $\mathrm{N}_{2} \rightarrow \mathrm{O}_{2}$ & $\mathrm{~N}_{2} \rightarrow \mathrm{O}_{2}$ & $\mathrm{~N}_{2} \rightarrow \mathrm{O}_{2}$ & $\mathrm{~N}_{2} \rightarrow \mathrm{O}_{2}$ \\
\hline
\end{tabular}

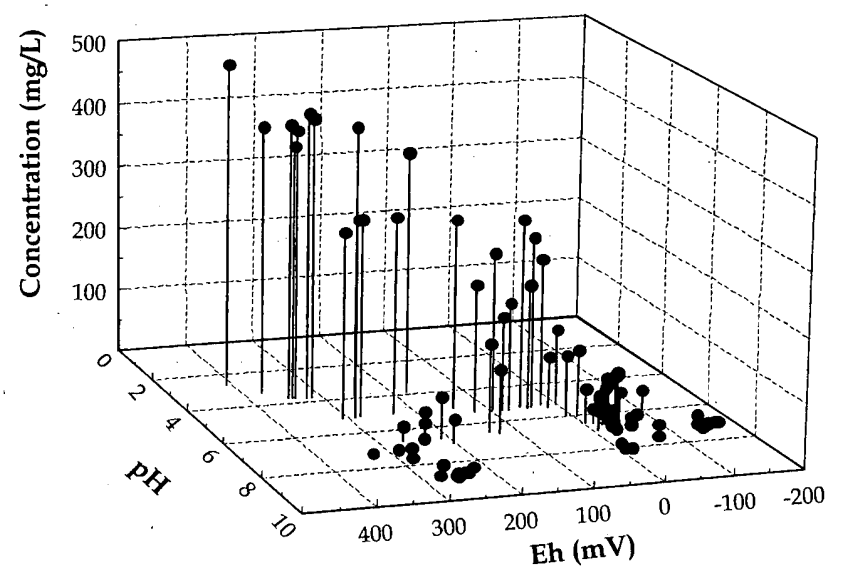

Fig. 7. Soluble $\mathrm{Zn}$ in soil water affected by $\mathrm{Eh}$ and $\mathrm{pH}$ in modified batch tests

for $\mathrm{Zn}$ concentration by inductively coupled plasma spectrometry (ICPS-8000, Shimadzu).

\section{RESULTS AND DISCUSSIONS}

\section{$p H$ and Eh Effects on Zn Mobility}

Figure 7 shows the soluble $\mathrm{Zn}$ concentrations as functions of $\mathrm{pH}$ and $\mathrm{Eh}$ for the modified batch tests, revealing that both $\mathrm{pH}$ and Eh control the mobility of $\mathrm{Zn}$ in clay liner system. With a decrease in $\mathrm{pH}$ and/or an increase in $\mathrm{Eh}, \mathrm{Zn}$ is highly dissolved in the soil water. In contrast, when $\mathrm{pH}$ increases and/or Eh decreases greatly, $\mathrm{Zn}$ is effectively immobilized in the soil. Although Zinc is not subjected directly to redox transformation due to its single valence state, its soluble levels are influenced by a number of processes that are regulated by redox potential. Analysis of the dominant redox reactions occurring in all test cases reveals that under oxidizing condition, $\mathrm{Zn}$ is associated with $\mathrm{Fe}(\mathrm{III})$ and $\mathrm{Mn}(\mathrm{IV})$ oxides and soluble phases. When $\mathrm{pH}$ increases more than 7.2, $\mathrm{Zn}$ precipitates as carbonate and hydroxides, and adsorbed on soil particles. If redox potential decreases so low that sulfate reduction reactions have occurred, the formation of zinc sulfide precipitation is considered responsible for the attenuation (Kamon et al., 2002).

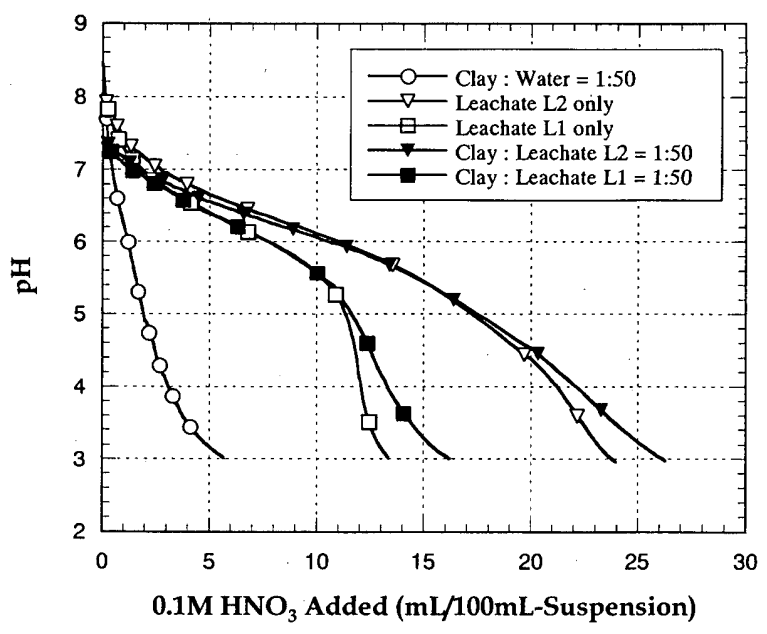

Fig. 8. Acid titration curve of Osaka marine clay dispersed in MSW leachates

It is found from the tests that the final $\mathrm{pH}$ values of soil suspensions in anaerobic conditions increase to be larger than the initial ones. Usually, the oxidation of organic carbon by anaerobic respiration pathways generates $\mathrm{HCO}_{3}^{-}$, and hence increases the alkalinity (Christensen et al., 1994). Further, both iron reduction and sulfate reduction utilize protons and, therefore, contribute to the generation of alkalinity in the environment of organism.

\section{Acid Buffering Capacity (ABC) of Clay-Leachate Systems}

To describe the acid buffering capacity of a ground water, acid neutralizing capacity (ANC) or alkalinity is traditionally used (Stumm and Morgan, 1996). ANC or alkalinity is a measure of the ability of a sample to neutralize strong acid and is reported as equivalents per liter or as $\mathrm{CaCO}_{3}$. In many aqueous systems, because alkalinity is commonly attributable to bicarbonate $\left(\mathrm{HCO}_{3}^{-}\right)$and carbonate $\left(\mathrm{CO}_{3}^{2-}\right)$, acidimetric titrations to an end-point of $\mathrm{pH} 4.3$ are suitable for ground waters with negligible concentrations of dissolved organic matter. For more complex waters, such as those rich in dissolved organic material, fixed end-point titrations will give inaccurate results (Hemond, 1990). Liner-leachate system is such a system which contains large amount of non-carbonate species that can accept protons, including $\mathrm{OH}^{-}$(and metal-OH complexes), $\mathrm{HS}^{-}, \mathrm{H}_{2} \mathrm{PO}_{4}^{-}$, ammonia, and silicate (Stumm and Morgan, 1996). Therefore, the acid buffering capacity (ABC) as mentioned in this paper is corresponded to the ANC or the total alkalinity determined by measuring $\mathrm{pH}$ as a function of titrated acid to a pH of 3.0 instead of 4.3.

Figure 8 shows the ABC of Osaka marine clay dispersed in MSW leachates and distilled water. It can be found that the Osaka marine clay dispersed in leachates $\mathrm{L} 1$ and $\mathrm{L} 2$ has a much higher $\mathrm{ABC}$ than that dispersed in distilled water. This means that leachate contributes greatly to the whole $\mathrm{ABC}$ of liner-leachate system than the clay as in the case of solid/liquid =1:50 in this work. As illustrated in Fig. 8, leachate-clay suspensions show an 


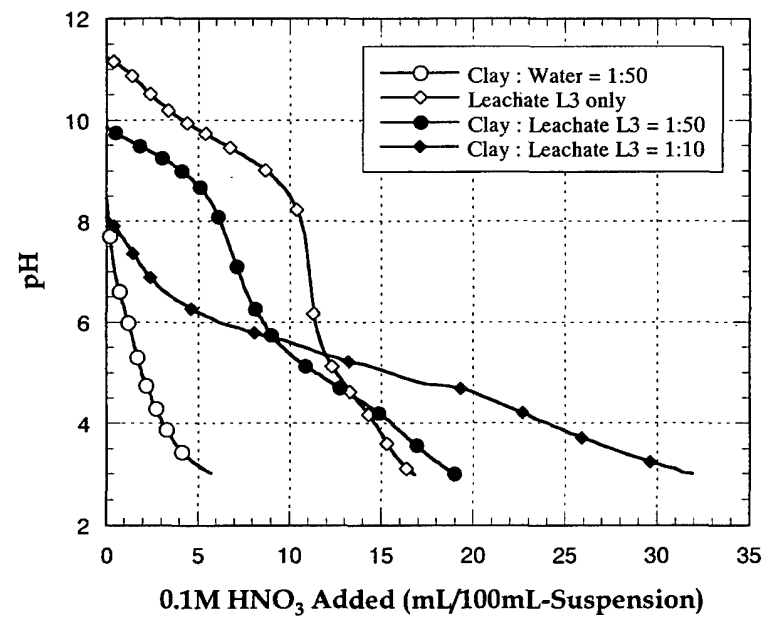

Fig. 9. Acid titration curve of Osaka marine clay dispersed in MSWIA leachate $\mathbf{L 3}$

elevated $\mathrm{ABCs}$ than the corresponding, pure leachates at $\mathrm{pH}<5.0$. This portion of increased $\mathrm{ABC}$ should come from clay minerals (see Table 1). From Fig. 8 it is clear that clay-leachate $\mathrm{L} 2$ possesses an $\mathrm{ABC}$ almost twice that of clay-leachate L1. Leachate L2 was collected from a landfill in operation, while leachate L1 collected from a landfill which has been closed for several years. This tends to prove that newly generated leachate has a higher acid buffering capacity than an old leachate, probably due to the fact that newly generated leachate has high carbonate and organic carbon load than the old one. Since the clay-leachate suspensions used in the titration tests have a solid-liquid ratio as high as 1:50, therefore, clay minerals contribute very few to the whole $A B C$ of the clay-leachate suspensions. With respect to an actual liner layer, soil particles become the major constituent proportion in the liner-leachate system, clay minerals of the liner soil are expected to provide considerable $\mathrm{ABC}$ in addition to the high $\mathrm{ABC}$ that leachate contributes.

Figures 9 and 10 show the $\mathrm{ABC}$ of Osaka marine clay dispersed in leachates L3 and L4, respectively; both of which were collected from an offshore landfill site in Osaka Bay that receives mainly the MSW incineration ash (MSWIA). Leachates L3 and L4 are characterized by high $\mathrm{pH}$ values, ranging from 11.23 to 11.32 . Typically, MSW incineration bottom ash has an initial $\mathrm{pH}$ ranging from 10.5 to about 12.2 . This is mainly due to the presence of calcium hydroxides produced from $\mathrm{CaO}$ hydrolysis in the bottom ash (The International Ash Working Group, 1997), as well as high content of alkaline metals and alkaline earth metals generally leachates out from MSW incineration ash (Tanaka and Hanashima, 1997). Again, test results indicate that clayMSWIA leachates have a considerable high $\mathrm{ABC}$ than the clay-water system. It is valuable to compare the $\mathrm{ABCs}$ of the three samples as shown in Figs. 9 and 10, namely, the leachate, the suspension with clay/leachate $=1: 50$, and the suspension with clay $/$ leachate $=1: 10$. With an increase in soil particle proportion, that is, an increase in the clay/leachate ratio, the $\mathrm{ABC}$ at $\mathrm{pH}=3.0$ increase

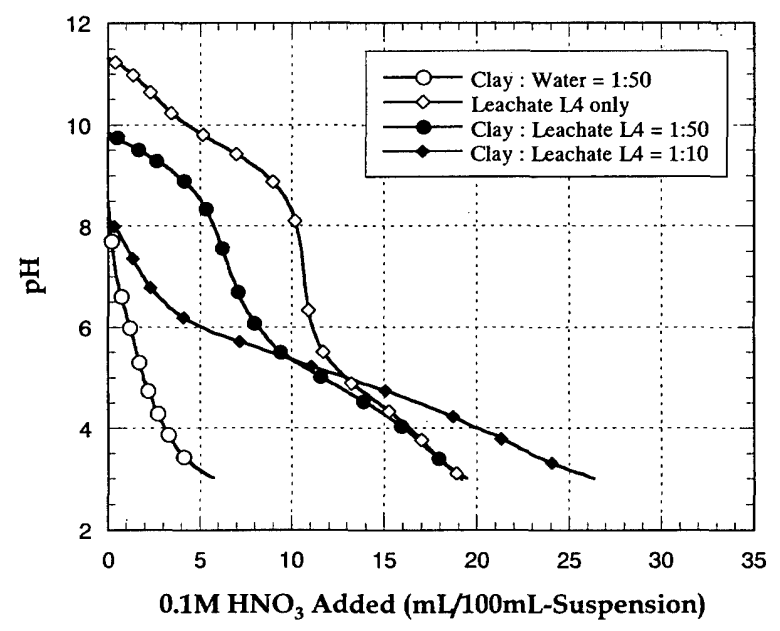

Fig. 10. Acid titration curve of Osaka marine clay dispersed in MSWIA leachate L4

considerably. This clearly supports the former deduction that, as in an actual landfill liner, clay minerals will also contribute greatly to the whole $\mathrm{ABC}$ of clay liner-leachate system in addition to the great contributions from the leachate.

With respect to the $\mathrm{ABC}$ distribution along $\mathrm{pH}$, apparent differences can be observed among the suspensions with different clay/leachate ratio. Figures 9 and 10 show that pure leachates have high hydroxide $\mathrm{ABCs}$ at $\mathrm{pH}>8.0$; which decreases or even disappears after the leachates have mixed with the clay in an increased clay/ leachate ratio. On the other hand, the $\mathrm{ABCs}$ of the clay-leachate suspensions at $\mathrm{pH}<6.0$ increase correspondingly. This phenomenon has twofold meanings. One is that the acid buffering capacity of a soil-leachate system can not be obtained simply by adding the $A B C$ of the soil with the $A B C$ of the leachate. Another meaning is that the hydroxide $\mathrm{ABC}$ of the leachate can be preserved in liner-leachate system, but at a lower $\mathrm{pH}$ range as in this case. Perhaps some reactions between the leachate and the soil components are responsible for the transfer of $\mathrm{ABC}$ from higher $\mathrm{pH}$ side to lower $\mathrm{pH}$ side. The most possible explanation is that the potassium and calcium hydroxides as commonly contained in MSWIA leachate react with soil components; as a results, some new minerals formed, which express stronger resistance to the acid attack than the hydroxides previously exhibited. If this is true, the following hypothesis can be made. After penetrating into the liner soil, MSWIA leachate with high $\mathrm{pH}$ values will accumulate, or store its hydroxide alkalinity in the liner soil through solid-liquid reactions, although it is not clear by far what reactions they are.

Figures 11, 12, 13 and 14 show the $A B C$ of Osaka marine clay dispersed in MSWIA leachates with microbe incubation (see Table 4). Q1 and Q3 used the original leachates L3 and L4, respectively, while Q2 and Q4 used the original leachates but added with nutrients for enhancement of microbial activities. Elevated ABCs of samples Q2 and Q4 in comparison with samples Q1 and Q3 derives obviously from the added nutrients components, 


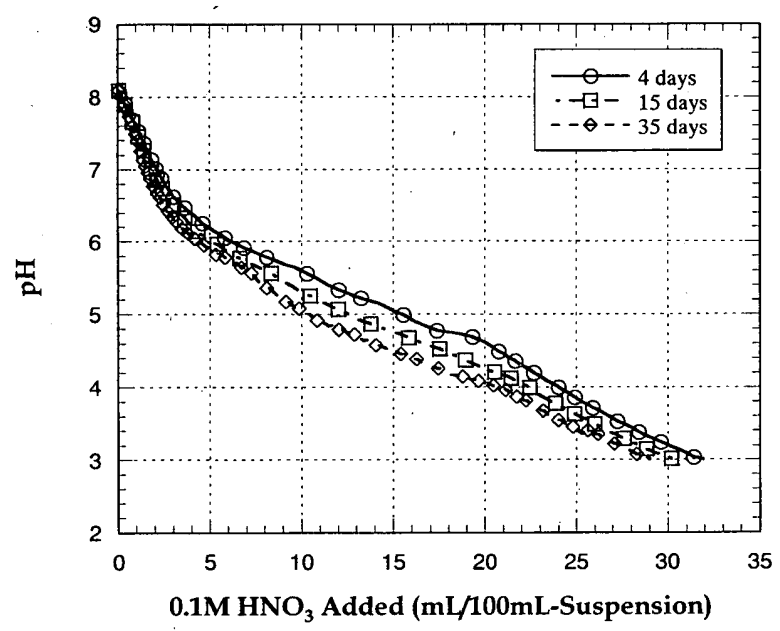

Fig. 11. Acid titration curve for sample Q1 with different incubation time

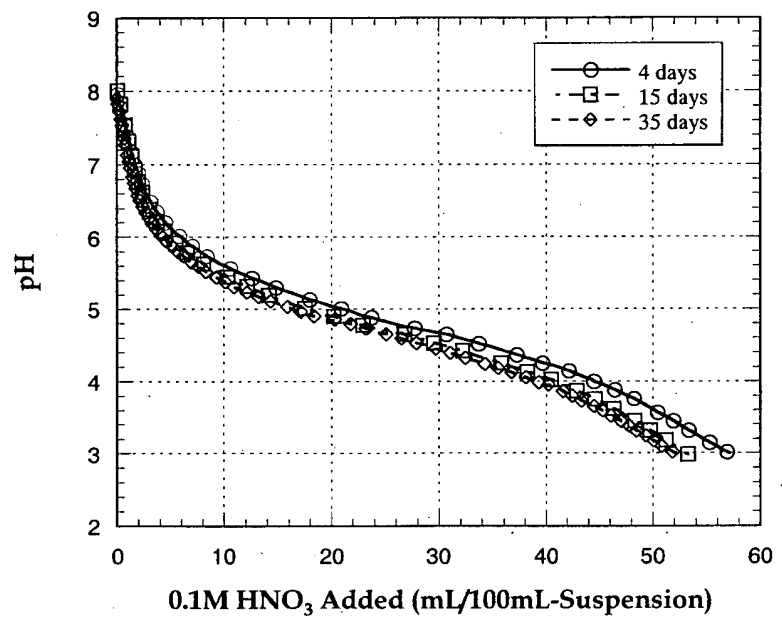

Fig. 12. Acid titration curve for sample $\mathbf{Q}^{2}$ with different incubation time

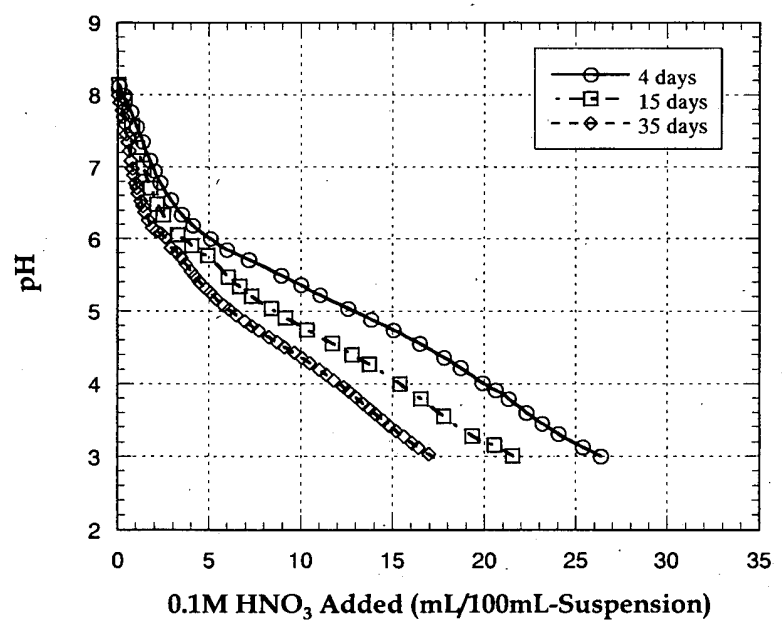

Fig. 13. Acid titration curve for sample Q3 with different incubation time

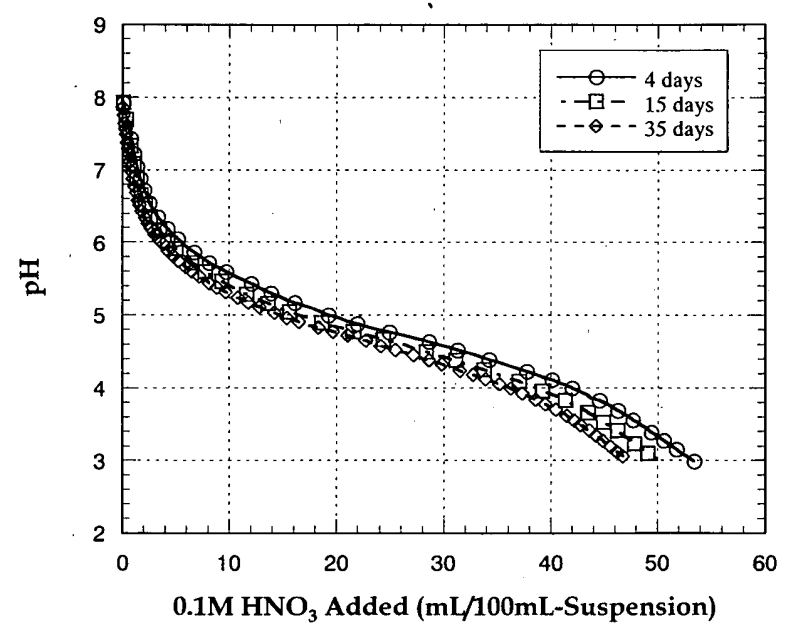

Fig. 14. Acid titration curve for sample Q4 with different incubation time

such as ammonia, $\mathrm{H}_{2} \mathrm{PO}_{4}^{-}$, and organic matter (see Table 4). This indicates that the complex soil-water system, such as the clay liner-leachate system, contains large amount of non-carbonate species that can accept protons and, therefore, attribute to a great increase in acid buffering capacity. With the increase of incubation time, the ABCs of samples Q1 to 4 decreased slowly. Perhaps the decrease in total organic carbon (TOC) is mainly responsible for the reduction in $\mathrm{ABC}$.

Alkalinity and $\mathrm{pH}$ tend to increase during reduction and to decrease during oxidation, since oxidized components are more acidic or less basic than their reduced counterparts (Bourg and Loch, 1995). It was reported that microbiologically mediated degradation of organic matter leads to an increase in total inorganic carbon and in increased alkalinity values (Lazzaretti-Ulmer and Hanselmann, 1999). No increased $A B C$ has been observed in this test. Contrarily, ABC decreases slowly with incubation duration as can be seen from Figs. 11 to 14 . This is probably because, the redox potentials measured in Q1 to Q4 during the 35 days anaerobic incubation period fall into an area ranging from 50 to $86 \mathrm{mV}$, which are not so low to launch strictly reducing reactions. Another reason may come from the continuous bubbling of the suspensions by nitrogen gas in this test, which might drive out the $\mathrm{CO}_{2}$ if produced, so that no carbonate dissolution could be expected. In the natural anaerobic soil-water interface as reported by Lazzaretti-Ulmer and Hanselmann (1999), microbiologically produced $\mathrm{CO}_{2}$ existed in a micro-environment that was closed from the atmosphere and, therefore, carbonate dissolution could be expected.

\section{Zinc Release with Decrease in $p H$}

Although as high as $1000 \mathrm{ppm}$ of $\mathrm{ZnCl}_{2}$ was added to the samples Q1 to Q4, no soluble $\mathrm{Zn}$ was detected out from the original.suspensions during 65 days incubation. This is because, the suspensions just as they were harvested before titration tests had $\mathrm{pH}$ values raging from 7.43 to 8.62 . Within this $\mathrm{pH}$ range, zinc exists as 


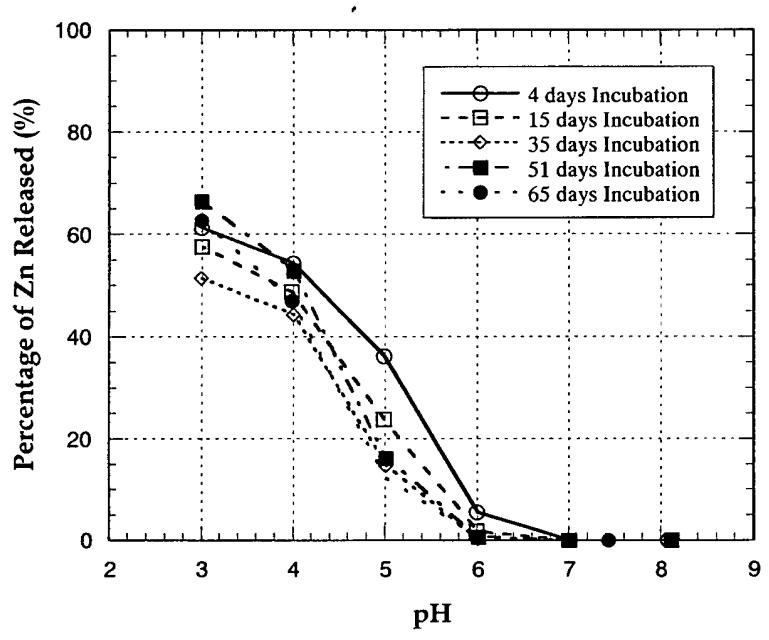

Fig. 15. Release of $\mathrm{Zn}$ vs $\mathrm{pH}$ in titration test for $\mathrm{Q1}$

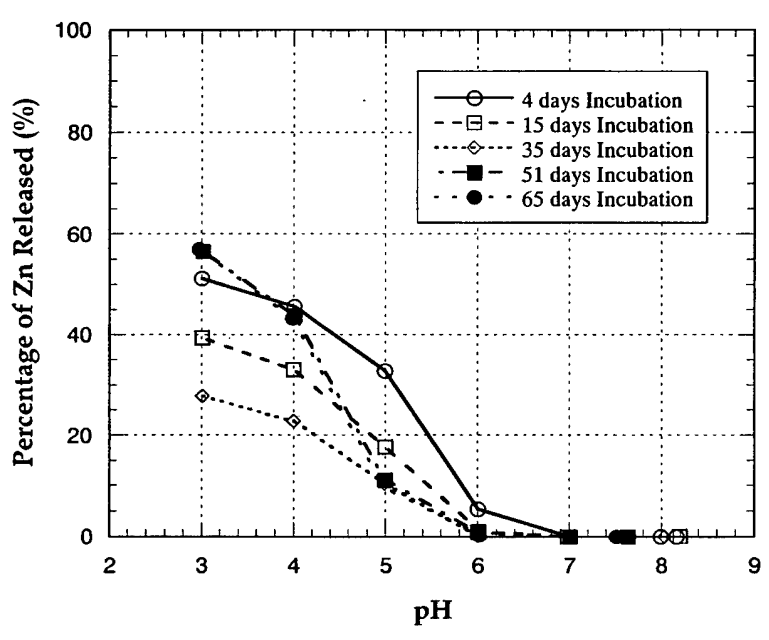

Fig. 16. Release of $\mathrm{Zn}$ vs $\mathrm{pH}$ in titration test for $\mathrm{Q3}$

hydroxide precipitates and adsorbed on soil particle surfaces. During the titration test on samples Q1 to Q4, after a specific $\mathrm{pH}$ value had arrived, $2 \mathrm{~mL}$ suspension was withdrawn out to measure soluble $\mathrm{Zn}$ concentration as soon as possible. The measured $\mathrm{Zn}$ concentrations are divided by the initial $\mathrm{Zn}$ concentration as $\mathrm{Zn}$ added, giving out a ratio that indicates the release percentage of $\mathrm{Zn}$ as shown in Figs. 15 and 16 for Q1 and Q3, respectively. Test results indicate that the lower the $\mathrm{pH}$ decreases, the more the $\mathrm{Zn}$ is released. Figures 15 and 16 do not only reveal the $\mathrm{pH}$ dependency property of $\mathrm{Zn}$ in clay-leachate system, but also illustrate how much acid is needed to reach a specific pH value if Figs. 11 and 13 are referred to at the same time. For instance, from Fig. 15, if around $20 \%$ of $\mathrm{Zn}$ is expected to be released, the suspension has to decrease its $\mathrm{pH}$ to around 5.0. From Fig. 11, it can be noted that, equivalent to $10 \sim 15 \mathrm{~mL}$ of $0.1 \mathrm{M}$ $\mathrm{HNO}_{3}$ according to $\mathrm{pH}=5.0$ is needed to bring about such a release event.

Microbial processes occurring in landfills result in anaerobic conditions which are characterized by very low

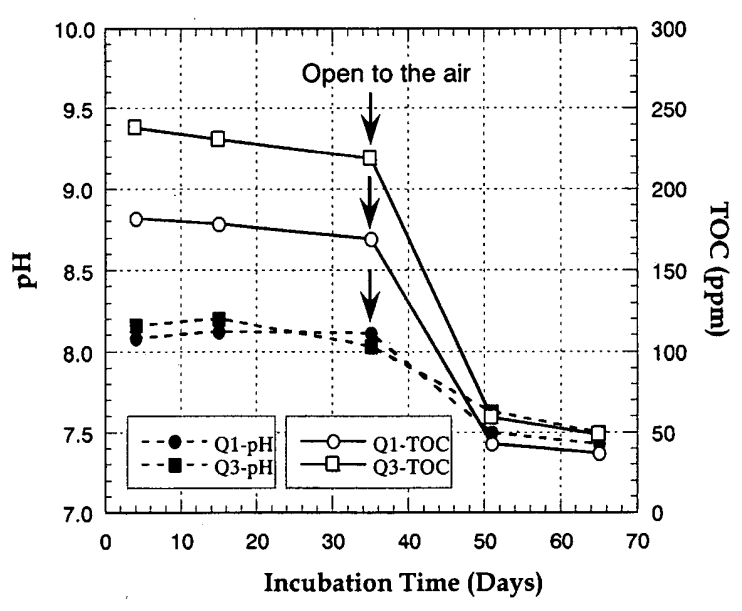

Fig. 17. Changes in $\mathrm{pH}$ and TOC with incubation time for $\mathrm{Q1}$ and Q3

redox potentials and neutral to weak alkaline $\mathrm{pH}$ conditions if decomposition of landfills comes to the methaneproducing stage. From Fig. 7 it is clear that these Eh and $\mathrm{pH}$ combinations favor an effective immobilization of $\mathrm{Zn}$ at landfill sites. In the long-term perspective, oxygen will intrude finally into the landfill. Most oxidation of organic carbon results in a net release of $\mathrm{CO}_{2}$, which will force the $\mathrm{pH}$ to decrease in a system that is not in equilibrium with the atmosphere. Therefore, there are new concerns that whether the metals immobilized at the previous stabilization stages exist as there were or they tend to be remobilized and leached out due to this acidification process.

In order to investigate if the oxidation of organic carbon will lead to a decrease in $\mathrm{pH}$ and to an elevated release of $\mathrm{Zn}$, samples Q1 to Q4 as shown in Table 4 were designed to change from anaerobic conditions to aerobic conditions after 35 days. During the first 35 days of incubation from the beginning of the test, Q1 to Q4 were bubbled continuously by nitrogen gas. After 35 days the soil suspensions were open to the air by removing all of the reactor stoppers. As a result, high content of oxygen contained in the air contacted with the suspensions, switching the original anaerobic conditions to aerobic ones. Figure 17 shows that after the bubbling gas changed from $\mathrm{N}_{2}$ to $\mathrm{O}_{2}$, TOC decreases rapidly because the oxidation of organic compounds under aerobic conditions occurs at a higher rate than under anaerobic conditions. As a consequence, a little decrease in $\mathrm{pH}$ is also observed (see Fig. 17). This proves that aerobic oxidation of organic carbon does lead to an acidification process.

As an acidification effect due to the accelerated oxidation of organic carbon in aerobic conditions, soluble zinc concentration of soil suspensions was increased after 35 days incubation (see Figs. 15 and 16). It should be noted that the soluble $\mathrm{Zn}$ after 35 days being greater than that measured at 35 days occurs only at a specific $\mathrm{pH}$ range of $\mathrm{pH}<5$. This seems that the oxidation of organic carbon tends to release elevated zinc at specific $\mathrm{pH}$ values, that is, at lower $\mathrm{pH}$ ranges. This result is consistent with that reported by Song and Muller (1999), who found that a significant release of heavy metals including $\mathrm{Zn}$ during 


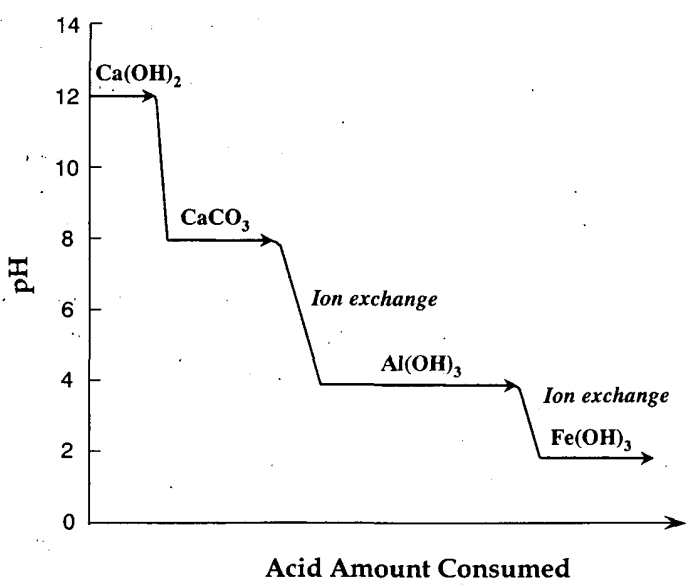

Fig. 18. Schematic curve of acid buffering processes in clay linerleachate system

the oxidation of anoxic sediments occurs only if $\mathrm{pH}$ decreases below 4.5. Above this $\mathrm{pH}$ value, heavy metals dissolved due to the oxidation of anoxic sediments, may be adsorbed onto freshly formed Fe and Mn oxide surfaces (Song and Muller, 1999).

From a long perspective, the ABC of both landfilled wastes and the bottom liner will control the aerobic acidification effects on zinc mobility. Table 1 lists the important acid producing oxidation reactions and the acid buffering reactions in wastes. The former tends to produce protons while the latter tends to consume protons. Organic oxidation reactions are considered to be the major reactions producing acid in MSW landfills.

The $\mathrm{pH}$ buffering mechanism of a solution can be explained simply as the followings. The $\mathrm{pH}$ of a solution decreases when protons are added, if there are no buffering substances available. If buffering substances exist, they will react with added protons until a new equilibrium is established, which will reduce the $\mathrm{pH}$ shift. After one buffering substance has been depleted, added protons decrease the $\mathrm{pH}$ until another new buffering substance start to react with protons added.

Figure 18 is a schematic curve of acid buffering processes in clay liner-leachate system, which combines two factors: the "intensity" and the "capacity" of the acid buffering. The vertical axis indicates $\mathrm{pH}$, which usually refers to the "intensity", while the horizontal axis, which refers to the capacity, indicates the amount of strong acid added. In case of MSW incineration ash landfill site, because high content of calcium hydroxides are present, the added protons are firstly consumed by neutralization reactions, and the $\mathrm{pH}$ of the system will remain constant. As long as $\mathrm{CaCO}_{3}$ is present, additional protons added will be consumed by dissolution reactions. Then the added hydrogen ions will be used to displace the exchangeable sites of clay minerals. This means ion exchange reactions can also consume dissolved hydrogen ions, representing certain buffering capacity (see Table 1). Ultimately, further addition. of acid leads to the dissolution of $\mathrm{Al}$ in clay minerals, and finally to the dissolution of ferric oxides. With regards to long-term effects, major processes consuming hydrogen ions in ecosystems include release of basic cations by decomposition of organic matter, specific anions adsorption, mineral weathering, and unbalanced reduction of oxidized components (Binkley et al., 1989).

With respect to a municipal solid waste landfill site, it is considered that the acid buffering processes occur similar to that illustrated in Fig. 18 except that the hydroxide neutralization stage is absent. Carbonate dissolution is the most important buffering mechanism in MSW leachate-clay liner system, which is responsible greatly for resisting the $\mathrm{pH}$ decrease, therefore the heavy metal release.

Belevi and Baccini (1992) investigated the ABC of landfilled municipal solid wastes. It was reported that 6 mol of acid are needed for $1 \mathrm{~kg}$ waste to reach $\mathrm{pH} \mathrm{7,}$ while the landfilled waste was estimated to produce $4 \mathrm{~mol}$ of weak acids in the worst case in the next 1000 years. Therefore, it was concluded that a remobilization of metals due to a $\mathrm{pH}$ decrease is not expected for at least many centuries since the alkalinity of the landfill body even after the intensive decomposition period is high enough to neutralize protons produced by organic carbon degradation to $\mathrm{CO}_{2}$ (Belevi and Baccini, 1992). The offshore landfills in Osaka Bay, Japan are characterized by high saturation because most part of the landfill bodies is immersed in sea water. Based on the results of Bozkurt et al. (2000) as shown in Table 2, it can be estimated that many thousands of years are needed for these offshore landfills to change from an anaerobic condition to an aerobic condition.

Bottom clay liner is located beneath the landfilled solid wastes. This means that the acid buffering capacity of the landfilled wastes are consumed previously, followed by the consumption of the buffering capacity of linerleachate system. From this viewpoint, it is better to consider the $\mathrm{ABC}$ of liner-leachate system as an additional preservation to the $\mathrm{ABC}$ of landfilled wastes themselves. Taking into account the facts that $\mathrm{pH}$ buffering capacities of both waste bodies and clay liner are very high, and that the landfills at offshore landfill sites in Japan are almost immersed under sea level, it seems that higher rate of remobilization of heavy metals due to lowering of $\mathrm{pH}$ at mature aerobic stage is not expected even in the future.

\section{CONCLUSIONS}

Based on the test results obtained, the following conclusions can be made:

(1) Both pH and Eh conditions control the mobility of zinc in Osaka marine clay. Low redox potentials and neutral to basic $\mathrm{pH}$ conditions in landfill sites tend to prompt the insolubilization of zinc in landfill liner, in particular in the case where the natural marine clay under strongly reducing conditions is used to serve as natural bottom liner at offshore landfill sites.

(2) Liner soil dispersed in landfill leachate has a high acid buffering capacity due to the high organic carbon 
and carbonate loads contained. Newly generated leachate has a higher acid buffering capacity than the aged leachate. Leachates from MSW incineration ash have high hydroxides alkalinity at $\mathrm{pH}>8$, which will be converted and stored as an alkalinity at $\mathrm{pH}<6$ after the mixing of the leachate with liner soil due to solid-liquid interactions.

(3) Zinc may be released out from soil-MSWIA leachate suspensions only if sufficient acid is added. It seems that both of the landfilled wastes and clay liner possess enough acid buffering capacity to consume the protons produced in organic oxidation reactions. Therefore, high levels of remobilization of heavy metals are not expected at the final aerobic decomposition stage.

\section{ACKNOWLEDGEMENTS}

Financial support from the Japan Society for the Promotion of Science (JSPS) for this study is acknowledged.

\section{REFERENCES}

1) Aburatani, S., Hayashi, Y. and Nishikawa, T. (1996): Offshore waste disposal by Osaka Bay Phoenix Project, Environmental Geotechnic (ed. by Kamon, M.), Balkema, 623-628.

2) Anderottola, G. and Cannas, P. (1992): Chemical and biological characteristics of landfill leachate, Landfilling of Waste: Leachate (eds. by Stegman, R. et al.), E F \& Spon, 65-88.

3) Belevi, H. and Baccini, P. (1992): Long-term leachate emissions from municipal solid waste landfill, Landfilling of Waste: Leachate (eds. by Stegman, R. et al.), E F \& Spon, 431-440.

4) Binkley, D., Driscoll, C. T., Allen, H. L. Schoeneberger, P. and McAvoy, D. (1989): Acidic Deposition and Forest Soils: Context and Case Studies in the Southwestern United States, SpringerVerlag, New York.

5) Bourg, A. C. M. and Loch, J. P. G. (1995): Mobilization of heavy metals as affected by $\mathrm{pH}$ and redox conditions, Biogeodynamics of Pollutants in Soils and Sediments (eds. by Salomons, W. and Stigliani, W. M.), Springer, 87-102.

6) Bozkurt, S., Moreno, L. and Neretnieks, I. (2000): Long-term processes in waste deposits, Sci. Tot. Environ., (250) 101-121.

7) Brookins, D. G. (1988): Eh-pH Diagram for Geochemistry, springer-Verlag.
8) Bureau of Port and Harbor, Tokyo Metropolitan Government, Japan (2001): Field Investigation of the Stabilization of Landfilled Waste Ground. http://www.kouwan.metro.tokyo.jp/gijyutsu/ users/chosa/gomi.pdf (in Japanese).

9) Christensen, T. H., Kjeldsen, P., Albrechtsen, H. J., Heron, G., Nielsen, P. H., Bjerg, P. L. and Holm, P. E. (1994): Attenuation of landfill leachate pollutants in aquifers, Crit. Rev. Environ. Sci. Tech., 24 (2), 119-202.

10) Christensen, T.H., Bjerg, P.L., Banwart, S.A., Jakobsen, R., Heron, G. and Albrechtsen, H. J. (2000): Characterization of redox conditions in groundwater contaminant plumes. J. Contam. Hydrol., 45, 165-241.

11) Farquhar, G. J. and Rovers, F. A. (1973):. Gas production during refuse decomposition, Water Air Soil Pollut., 2, 483-495.

12) Hemond, H. F. (1990): Acid neutralizing capacity, alkalinity, and acid-base status of natural waters containing organic acids, Environ. Sci. Tech., (24), 1486-1489.

13) Kamon, M., Zhang, H. and Katsumi, T. (2002a): Redox effects on heavy metal attenuation in landfill clay liner, Soils and Foundations, 42 (3), 115-127.

14) Kamon, M., Zhang, H., Katsumi, T. and Sawa, N. (2002b): Redox effect on the hydraulic conductivity of clay liners, Soils and Foundations, 42 (6), 79-91.

15) Kjeldsen, P., Barlaz, M. A., Rooker, A. P., Baun, A., Ledin, A. and Christensen, T. H. (2002): Present and long-term composition of MSW landfill leachate: a review, Crit. Rev. in Environ. Sci. Tech., 32 (4), 297-336.

16) Lazzaretti-Ulmer, M. A. and Hanselmann, K. W. (1999): Seasonal variation of the microbially regulated buffering capacity at sediment-water interfaces in a freshwater lake, Aquat. Sci., 61, 59-74.

17) Sarsby, R. (2000): Environmental Geotechnics, Thomas Telford.

18) Song, Y. and Muller, G. (1999): Sediment-Water Interactions in Anoxic Freshwater Sediments, Springer.

19) Stigliani, W. M., Doelman, P., Salomons, W., Schulin, R., Smidt, G. R. B. and Van der Zee, S.E.A.T.M. (1991): Chemical time bombs-Predicting the unpredictable., Environment, 33, 4-9 and 26-30.

20) Stumm, W. and Morgan, J. J. (1996): Aquatic Chemistry, 3rd ed., John Wiley, New York.

21) Tanaka, N. and Hanashima, M. (1997): High concentration of salts in leachate and mineralized waste disposed of in municipal solid waste landfill sites, J. Japan Society of Waste Management Experts, 8 (7), 481-485.

22) The International Ash Working Group (1997): Municipal Solid Waste Incinerator Residues, Elsevier.

23) Zhang, H. (2001): Redox effects on heavy metal mobility and hydraulic conductivity of clay liners at landfill sites, Doctoral Dissertation of Kyoto University, Japan. 